\title{
La villanía heroica de El Señor de los Cielos en la lucha contra un Estado anómico*
}

\author{
Ainhoa Vásquez Mejías ** \\ Recibido: mayo 20 de 2014 - Aceptado: septiembre 13 de \\ 2014
}

\section{Resumen}

Amado Carillo Fuentes, narcotraficante mexicano de los años 90, ha sido caracterizado como un sujeto dual: transformado en héroe por su pueblo y condenado como villano por el Estado mexicano. Su vida ha sido narrada en múltiples producciones como narcocorridos, películas, novelas y, recientemente, la telenovela El Señor de los Cielos. Si bien, en la novela del mismo nombre, publicada en el año 2013 por Andrés López, Carillo es descrito como un héroe, en la telenovela de Telemundo, deviene en villano contra el cual lucha el policía Marco Mejía. En ambas creaciones, no obstante, la institución del narcotráfico se presenta desde un código ético, en contraposición a la corrupción e impunidad con que se grafica al Estado. Ello provocaría que como espectadores de la telenovela simpaticemos con el villano antes que con el héroe, contraviniendo las reglas del melodrama clásico. Aventuramos que esto se debe a que reconocemos en el villano su ímpetu por sobrevivir en un medio adverso y su disputa contra un Gobierno incapaz de proteger a sus propios héroes. La telenovela, de esta forma, denunciaría la existencia de un Estado anómico al transformar al villano en el verdadero protagonista.

Palabras clave: héroe, villano, melodrama, estado anómico, narcotráfico.

\footnotetext{
- Este artículo forma parte del proyecto de investigación Narcoestética: apropiaciones de un modelo cultural méxicocolombiano para la constitución de un nuevo formato literario y audiovisual en Chile, dirigido por Danilo Santos, Pontificia Universidad Católica d Chile. Una primera versión fue presentado en el Colegio de México, en el marco del XL Congreso del Instituto Internacional de Literatura Iberoamericana (IILI) en junio del año 2014, bajo el título de Policía bueno/ policía malo: autoridades en el narcotráfico en novelas y telenovelas mexicanas.

** Pontificia Universidad Católica de Chile. Correo: aovasque@uc.cl
} 


\title{
Heroic Villainy of "El Señor de los Cielos" in the Fight against an Anomic State
}

\begin{abstract}
Amado Carillo Fuentes, a Mexican drug trafficker of the 90's, has been shown as a dual individual: Transformed into a hero by his own town of origin and sentenced as villain by the Mexican State. His life has been narrated in several productions as "narcororridos," films, soap operas, and more recently in telenovela "El Señor de los Cielos." Although in the novel with the same title, published in 2013 by Andrés López, Carillo is described as a hero, the Telemundo telenovela shows him as a villain persecuted by police officer Marco Mejía. In both creations, however, drug trafficking is shown from an ethical code in opposition to the State corruption and impunity. As viewers of this telenovela, we tend to sympathize with the villain and not with the hero, which goes against the rules of the classic melodrama. In our opinion, this may be due to the fact that we recognize the villain's vehemence to survive in an adverse environment and his fight against a government incapable of protecting its own heroes. The telenovela would then denounce the existence of an anomic State when the villain is transformed into the real leading protagonist.
\end{abstract}

Key words: Hero; villain; melodrama; anomic State; drug trafficking. 


\section{Introducción}

La bondad y la maldad se miden siempre desde su opuesto. No podemos decir que algo o alguien es intrínsecamente malo o bueno si no tenemos un parámetro desde donde ejercer la comparación. Ese es, al menos, el principio del melodrama. Una línea horizontal -al comienzo, bastante equilibrada- de fuerzas que se oponen. En un polo el bien, en el otro el mal. Esta visión maniquea, a lo largo del desarrollo, se inclina a favor del héroe, de lo positivo, de lo moral y políticamente correcto. Todo ello refiriendo al melodrama desde su estilo tradicional, por supuesto, en el que el condicionante básico es que el justiciero triunfará por sobre el villano, reponiendo un orden que se había perdido.

A menudo los héroes de las telenovelas nos caen bien. Siempre escogen a los actores más guapos y carismáticos, al que las mujeres desean y los hombres buscan imitar. Al contrario de las heroínas-víctimas, que muchas veces son mujeres tan buenas que llegan a parecer tontas al caer en las trampas más ridículas; los justicieros son seres con matices, virtuosos a veces, débiles en otros momentos. Son más humanos, se parecen más a nosotros. A los villanos, en cambio, podemos llegar a detestarlos. Esperamos ansiosos el momento en que el bien triunfe y los malvados obtengan su redención en el arrepentimiento, la locura o la muerte. Es que así es como hemos sido criados televisivamente: el gran final debe tener una dinámica de premio y castigo para sentirnos, como espectadores, reconfortados y seguros de que la justicia en el mundo existe y ello es gracias a personas buenas, leales y valientes que no claudican ante ningún peligro.

En la vida real Amado Carrillo Fuentes fue caracterizado desde la perversidad por el Gobierno, y desde la heroicidad por su gente. Como héroe fue reconocido por el pueblo que lo erigió como un nuevo Jesús Malverde, un Robin Hood criollo que dio oportunidades económicas a los marginados del Estado'. Como villano, en cambio, fue estigmatizado como traidor de telenovela que trasciende las pantallas. Fue acusado de sanguinario, inhumano, cruel y ambicioso. Considerado uno de los hombres más peligrosos y violentos de México, impuso su dominio como señor de la droga, extendiendo su reinado más allá de las fronteras nacionales al apoderarse del negocio en Colombia, luego de la muerte de Pablo Escobar y lograr transportar cocaína impunemente hacia Estados Unidos en su flota privada de aviones². Por esta razón fue bautizado como "El Señor de los Cielos" y su vida y sus acciones, cantadas y narradas en varias producciones: primero vino la película dirigida por Javier Montaño en el año 1997, luego la obra de teatro Hamlet, El Señor de los Cielos, escrita por el argentino Rubén Pires en el 2011 y, actualmente, la novela y telenovela del mismo nombre.

1 Tal como lo cantan varios narcocorridos: Nave 727 de Los cadetes de Linares, El Señor de los cielos de Voz de Mando, Carillo en la sangre de los Máximos de Sinaloa, Corrido de Amado Carrillo de Los Parranderos de Chihuahua, Cayó el Señor de los cielos de El As de la Sierra, entre muchos otros.

2 Para un estudio detallado de la vida de Amado Carrillo Fuentes y sus vínculos con las autoridades gubernamentales, Cf. Andrade Bojorges, 1999. 


\section{Metodología}

Con el fin de lograr un análisis detallado respecto a la representación que se ha realizado sobre el capo Amado Carillo Fuentes, principalmente, en la novela y telenovela "El Señor de los cielos", recurriremos a disciplinas variadas, tales como la literatura, la teoría del melodrama, la televisión y la comunicación, la historia de México, el derecho y Estado, entre otras. Esta elección corresponde al hecho de que la compleja personalidad del narcotraficante no puede ser explicada desde un solo punto de vista, así como el narcotráfico, en cuanto industria, tampoco es posible de ser aprehendido desde una única línea, puesto que se entrelazan en su desarrollo la historia, la medicina, el rol del Estado, el periodismo, así como sus representaciones ficcionales. Por estas razones, el presente trabajo se circunscribe en el campo de investigación de los estudios culturales, debido a su carácter interdisciplinario.

Nos valdremos, así, de esta disciplina para dar cuenta de la creación de significados en torno a las producciones relacionadas con "El Señor de los cielos" y la crítica que estas hacen acerca de un Estado, que hemos denominado, anómico. Estudiar la construcción que se está haciendo de este emblemático personaje, así como su nexo con el aparato gubernamental, resulta fundamental para entender también la cultura actual, puesto que su representación no es inocente, por el contrario, busca generar determinados significados en un orden simbólico y desde ahí, cuestionar a la sociedad completa; tal como señala Stuart Hall (1997) "la representación es una parte esencial del proceso mediante el cual se produce el sentido y se intercambia entre los miembros de una cultura" (p. 2). En los siguientes apartados intentaremos desentrañar lo que tanto la literatura como la telenovela están queriendo visibilizar y transmitir a los lectores y espectadores, a través de estas ficciones.

\section{Damián Torres, el héroe trágico}

El Señor de los Cielos, en la novela del 2013 escrita por Andrés López -el mismo autor de El cártel de los sapos-, es el verdadero héroe. En ningún caso un héroe cualquiera, sino uno trágico, cual personaje sacado de un drama griego en el que el cambio de su fortuna, desde la riqueza a la miseria, se produce por un destino trazado de antemano por fuerzas sobrenaturales y que el personaje, debido a un error de juicio, induce ${ }^{3}$. Damián Torres (sobrenombre de Amado Carrillo Fuentes en alusión al seudónimo con el que ingresó a Chile: Jorge Torres), como todo héroe tiene un origen mitológico que lo predispone desde su nacimiento. No nos referimos con ello al primer nacimiento como niño pobre y débil por el hambre, en un pueblo pequeño como Badiraguato, Sinaloa; sino al segundo nacimiento, cuando aquejado por la enfermedad de brucelosis, Rosalba, su madre, desafía a la religión

3 Aristóteles en su libro Poética (ver Pimentel, en línea) define al héroe trágico como: "no eminentemente virtuoso y justo, cuya desgracia, sin embargo, sobreviene, no debido al vicio y la depravación, sino por un error de juicio o una debilidad de aquellos que gozan de gran reputación y prosperidad [...] el cambio en la fortuna del héroe no debe ser de la miseria a la felicidad, sino al contrario, de la felicidad a la miseria; y la causa de esto no debe estar en alguna depravación sino en algún grave error de su parte. 
católica y lo lleva con Calixto, el curandero yoreme que da su vida para salvarlo. La Parca, la muerte, lo busca para llevárselo, sin embargo, dos águilas la distraen y detienen:

Damián Torres, fueron los mensajeros de Dios o de la Virgen o del patrón... realmente no estoy seguro. Sólo sé que fueron los mensajeros de alguno de ellos los que te salvaron... el viento, las nubes. Tu vida siempre estará ligada a esos elementos. Siempre serás un hombre que vivirá y morirá en las alturas: Siempre serás el Señor de los Cielos. En ese instante el alma de Calixto, el indio yoreme, se despojó de su cuerpo para alojarse en el de Damián Torres, y éste se convirtió en un hombre con dos almas: una tan noble como el pan, otra tan mala como la maldad misma ${ }^{4}$. Al menos eso cuenta la leyenda (López, 2013, p. 31).

Ambas águilas lo sobrevolarán cada vez que corra peligro. Estas aves lo harán transformarse en un hombre valiente, atrevido y entregado a su destino. Con agallas desde pequeño y sin temor a la muerte, lo mismo es capaz de ir a recoger la pelota que se ha caído en un pozo para poder seguir jugando, que arriesgar su vida al ponerse a la par de Pablo Escobar, el capo más importante y violento del mundo. Como heroína de telenovela, Damián es devoto de la Virgen de Guadalupe "Virgencita, sé que soy un pecador, pero también sé que es a los pecadores a los que más abrazas en tu pecho" (López, 2013, p. 153), como todo narco lleva un rosario en su cuerpo, en el cuello o amarrado en el tobillo.

Preocupado desde niño por los problemas de su gente, descubre en el narcotráfico la forma de escapar de la miseria y ayudar a su familia: "Damián creció viendo la buena vida de los narcos y de sus familias. Además vio que también llevaban un poco de bienestar a su pueblo, donde la ley, el orden, el Estado y la mismísima Revolución no habían llegado ni llegarían jamás" (López, 2013, p. 22). Así, deja el colegio para aprender del negocio de la marihuana en el que su padre trabajaba y pronto se asocia a don Benito, uno de los capos más importantes de la región y su padrino de matrimonio, para mover la droga y con ello liberar al pueblo del hambre y la pobreza. Su gente les agradece: "El líder de los campesinos agradece en nombre de todos sus compañeros el buen corazón de don Benito, menciona que ni ellos ni sus familias tenían ni para una tortilla y que gracias a él, al Colorado y a don Damián hoy tienen con qué comer" (López, 2013, p. 173).

En el camino se hace de enemigos poderosos, otros capos de la droga que disputan territorios; sin embargo, Damián es tan fuerte que ninguno de sus detractores logra vencerlo. Como héroe su lucha es contra su destino y contra él mismo. Como héroe griego su fortuna deviene en miseria, por cuanto comete errores de juicio al decidir someterse a una intervención quirúrgica para cambiar su rostro. Esta acción será el culmen de sus hazañas y la cita con su destino trazado: "Moría el Señor de los Cielos y con él la leyenda del Robin Hood mexicano, el protector de los humildes, el que había ofrecido techo y comida a muchos que antes no lo tenían" (López, 2013, p. 288). El héroe del pueblo solo se rinde ante la fuerza del destino.

4 En ese sentido, también podría ser definido como un héroe de tragedia isabelina, por cuanto, su caída no ocurre por debilidad o por juicio equivocado, sino por ese componente de maldad que presenta. "Héroe y villano se funden en uno y el mismo" (p.8), tal como indica la académica Laura Rosa Pimentel (en línea) respecto al héroe, sería el rasgo de villanía el que lo haría sucumbir. 


\section{Aurelio Casillas, el villano}

Este héroe literario trasladado a un contexto televisivo, no obstante, pareciera devenir en villano. En esta lucha dicotómica entre el bien y el mal, propia de la estructura melodramática, Aurelio Casillas, alter-ego de Carillo Fuentes, es el malvado y despiadado Señor de los Cielos. Su contraparte, el héroe bondadoso, es el policía y comisionado antidrogas que lo persigue, Marco Mejía. Se define, así, desde el género de telenovela policiaca, por cuanto el personaje principal es un policía que cumple el rol del héroe siguiendo las pistas para atrapar al criminal y en el que se recurre a situaciones como homicidios, asaltos, accidentes y fraudes, donde el héroe constantemente corre peligro de muerte frente al astuto villano (Cf. Munizaga, 1975; Sepúlveda, 2003; Trejo, 2011).

Como en toda telenovela, arraigada en un contexto de melodrama, los personajes "son tipificados y opuestos, representan una contraposición de valores que se manifiesta en los hechos y en las palabras. Por un lado, el héroe y la heroína y, por el otro, los villanos, sin que medie entre ellos una reconciliación. Los héroes siguen conservando sus valores positivos, su pureza y los malvados continúan representando la transgresión a esos códigos morales" (Trejo, 2011, p. 43). Marco Mejía, el justiciero, buscará por todos los medios detener el avance de Casillas en el control de la droga para salvar al país de lo que él considera un gran peligro para la salud, así como detener la violencia excesiva del capo. Valiente y temerario, desde el primer capítulo lo vemos desplegar un inmenso operativo con el fin de capturarlo.

Por lo general los héroes, no obstante, no son cien por ciento virtuosos; a pesar de ser hombres de buen corazón, "generalmente está confundido, asustado, es infiel y es manipulado por un entorno familiar que le impide entregarse al verdadero y puro amor que siente" (Fuenzalida, Corro y Mujica, 2009, p.25). Este héroe no es la excepción, puesto que, de declarar su gran amor por Eugenia, su novia periodista, rápidamente se enamora de su compañera policía colombiana, Leonor, quien lo secunda en sus acciones contra la maldad de Casillas, transformándose en la heroína de la telenovela que continuará su legado y honrará su memoria en la segunda temporada.

A la par de ello, Marco es un hombre débil, por cuanto, se vuelve preso de su sed de venganza. Su lucha contra el villano no es solo un asunto de salud pública, como lo hace ver, sino que también hay un fuerte componente de odio, ya que Casillas ha torturado y asesinado a su padre, Eduardo Cartagena ${ }^{5}$, un agente encubierto de la DEA que Aurelio descubrió: "Tú cazaste, torturaste y mataste a mi padre y lo vas a pagar", lo amenaza en un episodio. La venganza, es un motivo melodramático por excelencia y muy utilizado en

5 En la vida real el Agente Especial Enrique Camarena, torturado y asesinado en el año 1985 por mandato del capo Rafael Caro Quintero. En el año 2013, la revista Proceso puso en duda la versión oficial y publicó una entrevista con el exagente de la DEA, Héctor Berrellez, quien aseguró que su asesinato fue producto de un acuerdo entre el Cártel de Guadalajara y la Agencia Central de Inteligencia (CIA), implicada con el narcotráfico mexicano y que, también, participó en la tortura del Agente antinarcóticos (véase http://www.proceso.com.mx/?p=355922 y http://www.excelsior.com.mx/nacional/2013/10/12/923092). 
producciones como La madrastra, Cuna de lobos, Fuego en la sangre, Amor bravío, entre otras telenovelas en que el móvil de heroínas y héroes es la sed de justicia.

A pesar de que se muestra como un personaje inestable emocionalmente al debatirse entre el amor de Eugenia y de Leonor y que su móvil principal es la venganza, no por ello el héroe pierde cualidades como la honestidad, la lealtad, su preocupación por los demás, la valentía, la fuerza, la inteligencia, entre otros rasgos morales expresados por la teórica Marcia Trejo (2011). Una de sus principales características, además, es su confianza ciega en la justicia. Desde los primeros capítulos expresa que no quiere que Aurelio sea asesinado, sino que pague con su extradición a una cárcel estadounidense, los crímenes que ha cometido ${ }^{6}$. A pesar de que ello no ocurre y que, por el contrario, cumple una condena mínima, Marco no pierde su fe en las autoridades.

Mientras el comisario Mejía es el retrato del bien, Aurelio Casillas, el villano, encarna todo lo negativo, el mal. Algunas de las características aportadas por Trejo (2011) para definir a los antagonistas señalan que pueden ser hipócritas, maquiavélicos, superficiales, delincuentes, egoístas, mentirosos, con marcada inclinación al erotismo, dominantes, violentos, utilitaristas, vengativos, chantajistas, ambiciosos, manipuladores. A ello José Enrique Monterde (1994) agrega que simbolizan la ambición, el vicio y la prepotencia. Así como a Mejía lo vemos actuar con heroísmo desde el primer capítulo, Aurelio desde el inicio se refleja como un ser despiadado que le exige a su hijo Heriberto que dispare al perro de su hija Rutila para probar su puntería, un traidor al renegar de su amistad con Pablo Escobar cuando este le pide que ayude a su familia, un infiel que engaña a su esposa con otras mujeres sin pudor alguno.

Aurelio Casillas, como un potente villano de telenovela, se caracteriza como un hombre egoísta y ambicioso que no duda en traicionar o asesinar a quienes se le opongan en su intento por transformarse en el único capo de la droga en México. Así, a lo largo de su primera temporada, Casillas le pide matrimonio a Ximena solo para poder asesinar a Isidro Robles, quien fuera su socio y competencia, en el momento en que este se descuida creyendo en su amistad sincera; planea el secuestro de su amante Mónica para ganarse la confianza de su enemigo, Guadalupe Robles; lanza de la azotea de un edificio a su abogado y amigo "El Turco"; elimina a su padrino y suegro "Don Cleto", a quien le debe sus conocimientos en el negocio ${ }^{7}$, así como intenta asesinar a Mónica por interferir en sus planes.

A la par de estas agresiones y asesinatos particulares, Casillas es caracterizado como el culpable de todos los males del país, culpable de todos los crímenes que ocurrieron durante su dominio como capo de la droga. Es el caso del atentado que casi cobra la vida del periodista y director del diario La Tarde, Jesús Linares ${ }^{8}$; la muerte del candidato

6 "Yo lo quiero preso, no quiero que me quiten el placer de verlo reducido, hundido, en la cárcel como debe"

7 En la vida real su tío Ernesto Fonseca Carrillo, "Don Neto", uno de los jefes del Cártel de Guadalajara, quien, se encuentra libre desde agosto del 2013.

8 Periodista Jesús Blancornelas en la vida real, fundador del semanario ZETA y el periódico ABC, quien, 
presidencial Licenciado Colmenares ${ }^{9}$, la muerte del Cardenal Pastrana ${ }^{10}$, entre otros sucesos históricos que en la realidad se generaron por otros cárteles de droga y asuntos políticos que nada dicen en relación con las prácticas de Carrillo Fuentes.

Así, como en todo melodrama, la lucha entre buenos y malos es extensa. El héroe recurre a todas las estrategias posibles para alcanzar la justicia, mientras el villano se vale de todos los recursos con el fin de causar más daño y concretar sus ambiciones. Como toda telenovela, el melodrama tiene un componente moral muy fuerte, sobre todo en el caso de las telenovelas policiales como esta. La teórica del género Giselle Munizaga (1975) señala que la teleserie policial:

[...] es la representación de un acontecimiento social, pero por encima de ellos es también una ideología y una moral. Representa un modo de recortar un trozo de realidad y representa, a la vez, un modo de recrear ese trozo de realidad [.... . El acontecimiento social representado en las teleseries policiales es la represión de un acto delictual (p. 76).

Tomando en cuenta esta moral resulta bastante extraño para los espectadores identificarse con el villano y no con el héroe, como ocurre a menudo. Si bien, muchas veces el malvado puede no resultarnos del todo despreciable, por cuanto indica el académico José Enrique Monterde (1994): "junto al rechazo, nos moverá también una cierta fascinación: será la atracción del abismo por su forma de encarnar múltiples pulsiones agresivas, lo cual repercutirá en que no necesariamente se nos aparezca como repulsivo físicamente" (p. 61), El Señor de los cielos no solo no nos parece repulsivo físicamente (puesto que escogieron a uno de los galanes más cotizados), sino que nuestra atracción por él, como televidentes, es incluso más fuerte que la seducción que puede provocarnos el policía justo y valiente.

Aventuramos que ello puede deberse, principalmente a dos razones imbricadas que analizaremos a continuación: la primera es que, tal como se demuestra con mayor énfasis en la novela, el narcotráfico como institución ha remplazado al Gobierno y con ello se ha desplazado el polo de la bondad hacia los criminales. La segunda, presente sobre todo en la telenovela, es la decepción e incredulidad de los ciudadanos respecto a un Estado

en noviembre de 1997 fue víctima de un ataque por parte de sicarios de los hermanos Arellano Félix, porque realizaba una investigación sobre los inicios y redes de este cártel.

9 Seudónimo utilizado en la telenovela para referir el asesinato de Luis Donaldo Colosio, candidato presidencial del PRI, baleado en el año 1994 en plena campaña en la ciudad de Tijuana. Si bien, la historia oficial señala que fue asesinado por Mario Aburto, hasta el día de hoy existe la sospecha de que el magnicidio fue ordenado por el entonces Presidente de la República, Carlos Salinas de Gortari (véase http://www.nexos.com.mx/?p=15685).

10 En la realidad el Cardenal Juan Jesús Posadas Ocampo, asesinado en el año 1993 en el aeropuerto de Guadalajara. Según Hernández (2014) la versión oficial señaló que el homicidio se produjo luego de un fuego cruzado entre los hermanos Arellano Félix y Joaquín Guzmán Loera, "El Chapo". La autora, no obstante, indica que el Cardenal recibió 14 balazos directos y a corta distancia, argumentando, además, que Benjamín Arellano Félix, en una declaración ministerial rendida el 15 de abril del 2011 ante la PGR, confesó que Rodolfo León Aragón (en ese entonces jefe de la Policía Judicial), junto a integrantes de su comando, asesinaron al prelado obedeciendo una orden superior del gobierno, porque este proporcionaba armas a la guerrilla. 
benefactor y fuerte, hasta tal punto que los héroes, ligados a lo estatal, sobrevienen en seres débiles e indefensos cuyo único destino es la muerte: un fracaso de los metarrelatos, el derrumbe de toda esperanza frente a un Estado anómico ${ }^{11}$.

\section{En los negocios chuecos solo triunfa el que es derecho}

Es común, en una estructura melodramática, enfatizar la función de la familia como protectora frente a las adversidades de la vida pública. Tanto las situaciones como los personajes destacan virtudes como la abnegación, el deber, la capacidad de enfrentar el sufrimiento, la generosidad, la devoción a las causas en que se cree, optimismo y confianza en lo divino. Los villanos siempre serán los que busquen atentar contra esta estructura valorativa, mientras los héroes lucharán incansablemente por perpetuarla. Así, la telenovela se constituye, en cierta medida, en una escuela de moralidad al retratar valores inmortales: no importa cuánto cambie la sociedad, hay cosas que se mantienen, como el amor a la familia y la fe en las instituciones.

En una telenovela policial tradicional el héroe sería el estandarte de aquellos valores. Amparado por una institución mayor que da confianza y seguridad, que lo apoya en su proceder y lo secunda en su lucha contra los criminales, el agente justificaría su fe ciega en un aparato estatal mayor, puesto que sabe que, independiente de su pelea personal hay muchos como él que están dispuestos a dar la vida por defender a su pueblo. Sabe que él puede arriesgarse e, incluso, morir por sus ideales, ya que el Estado seguirá existiendo. Él es solo una pieza dentro del engranaje de una sociedad que funciona gracias a sus instituciones.

Tanto en la novela como en la telenovela, en cambio, las fuerzas gubernamentales son nulas. Es solo la lucha de un individuo particular, a quien lo mueve una sed de venganza, en contra de un aparato tan poderoso que ha sobrepasado al mismo Estado. Este aparato, esta institución en la que se ha transformado el narcotráfico en las narraciones, ha tomado de este ideal de Gobierno ciertas características positivas que hace a la gente sentirse nuevamente protegida por algo superior. El narcotráfico, de esta forma, remplaza la institucionalidad del Estado. Protectores de los suyos, los capos son firmes, autoritarios, pero no por ello menos cariñosos y preocupados del bienestar de su gente. La familia nuclear es el espacio fundante de una familia mucho mayor que incluye a los empleados y los pobladores de su territorio.

La familia es lo primero. Por ella se realiza toda clase de acciones en pos de su felicidad. "Mi vida es mi familia" (López, 2013, p.15), indica Torres en la novela. A pesar de tener otras mujeres, su esposa Ximena, para Casillas en la telenovela, lo es todo, tal como se demuestra cuando su amante Mónica le ofrece sacarlo de la cárcel para huir

11 Adoptamos la noción de "Estado anómico" referida por Peter Waldmann (2003) y explicada por José G. Giavedoni (2012) "El Estado latinoamericano, por medio de una sistemática violación de sus normas por parte de sus propias agencias, genera una sensación de incertidumbre y desconcierto que resulta en una total ausencia de reglas claras que proporcionen una orientación al comportamiento social" (p.94). 
juntos y él se niega "¿de qué fregados te va a servir un hombre que no te ama como amo a Ximena?". De la misma manera, el amor por sus hijos, por su madre y su hermano lo pone en riesgo más de una vez; sin embargo, él está dispuesto a perder la vida por ellos. En la telenovela, minutos antes de la intervención en la que se cambiará el rostro, Aurelio le declara su cariño a Víctor, su hermano: "Eres muy importante para mi vida. Sangre de mi sangre". Así, queda demostrado que a pesar de toda la violencia la sangre que va por dentro es la que importa; la sangre que une, no la que se derrama frente al enemigo y divide; la que hermana, no la que provoca guerras y venganzas ${ }^{12}$.

De la misma manera, tanto los empleados como la gente que habita el territorio del capo son una extensión de esa familia a la que hay que proteger por sobre todo. Es por ello que, tanto Torres como Casillas pagan altas sumas de dinero a quienes les colaboran con su silencio o a quienes demuestran su lealtad hacia el patrón: "varios billetes de alta denominación eran el sello que garantizaba la seguridad que por años le habían proveído" (López, 2013, p.52). Muchos de sus subalternos, incluso, mueren por protegerlo y él, a cambio, promete recompensar a sus familias. Nadie que apoya y ayuda al Señor de los cielos queda desamparado. La fidelidad y la valentía se pagan con dinero y protección para las generaciones futuras. Como los hombres que van a las guerras, la institución del narcotráfico les depara una recompensa que ni siquiera el Estado les provee a los suyos. Baste recordar la soledad absoluta en el funeral de Marco Mejía, quien luego de dar su vida por atrapar a Casillas, ni siquiera recibe homenajes gubernamentales.

En la novela, principalmente, es tan grande la lealtad y simpatía que proyectan estos capos como Torres y don Benito, que los mismos policías se enfrentan ante la dualidad del deber y la amistad. El infiltrado Juan Marcos ${ }^{13}$ presenta esta ambigüedad: "Después de haber compartido con don Benito y de conocer su lado más humano, a Juan Marcos le duele tener que traicionarlo porque el viejo ha llegado a inspirarle cariño y hasta a recordarle a su padre, pero las circunstancias lo obligan a mantener una doble vida y se le quiebra el corazón en dos pedazos que pelean entre el deber y la amistad" (López, 2013, p. 194).

El mismo deber que mueve a estos capos a proteger a los suyos es resultado de un código ético firme en el que la familia siempre es lo primero, en la que se respetan las plazas, se dividen los territorios, y la honestidad y lealtad fungen como estandarte. En la novela prometen que: "nunca se meterían con las familias de ellos ni con las de los enemigos, se respetarían las plazas, los contactos y, como principio, se exigía honestidad en los negocios" (López, 2013, p.117). Don Benito es el mejor ejemplo de ello, a quien se describe constantemente como un hombre de honor al que todos quieren y respetan, ejemplo a seguir de Damián Torres quien lo reconoce como su padrino, como su mentor y como la persona que más admira, junto con El Colorado. A pesar del peligro que corre al ser perseguido por los policías, Damián busca despedirse de sus padrinos antes de la

12 Uno de los espacios preferidos del melodrama siempre es la casa y su concreción en la familia. La familia, según Monterde (1994), es el lugar de concentración de los afectos y sentimientos.

13 En la vida real el mismo agente Camarena referido anteriormente. 
cirugía: "Si la vida nos pega tanto como para olvidar despedirnos de la poca gente que vale la pena, pues mejor estar muerto... porque vivos, no valemos nada" (López, 2013, p. 59).

Así, tanto la familia como los empleados y vecinos respetan y quieren a sus capos porque han demostrado que son como ellos, que salieron desde abajo como ellos, que lucharon por hacer de su vida algo mejor y darles a los suyos bienestar. Porque son derechos, porque saben pagar favores, porque los protegen de los peligros y son generosos, porque no se olvidan de su gente. Porque, aunque el Gobierno no se acuerde de ellos ni para los terremotos, los grandes narcos están ahí para darles trabajo, oportunidades de surgir, para prometerles una vida corta pero que vale ser vivida por cuanto mueren con honor: "La gente sigue al jefe no porque le tenga miedo, sino porque le tiene ley, porque ha luchado junto a él, ha ganado junto a él, se ha jodido junto a él... se ha reído y llorado junto a él” (López, 2013, p.49) le recuerda Dagoberto a Damián"

\section{La denuncia de un Estado anómico}

Al contrario de este aparato que funciona con base en la lealtad y el apoyo mutuo, donde los narcotraficantes necesitan del pueblo como el pueblo requiere del amparo de sus capos, el Gobierno se muestra -tanto en la novela como en la telenovela-como una institución en crisis, como un Estado anómico que no provee ningún tipo de garantía de seguridad y orden público, sino, por el contrario, es responsable de la inseguridad social y de un sinfín de irregularidades. No es posible confiar en nadie puesto que todos buscan su propio provecho. Los hombres más rectos e intachables terminan siendo colaboradores del narco, simplemente por agarrar una tajada de dinero y sentirse, también, protegidos por los dueños del territorio. El Estado no representa ninguna garantía de bienestar, la corrupción y la impunidad son las características que lo definen. Los que prometen perseguir son aliados, como es el caso del General del Ejército Jiménez Arroyo "el letrudo" en la telenovela ${ }^{15}$, comisionado presidencial antidrogas, que se aprovecha de su amistad con Casillas para ascender en el poder político.

Tal como en el caso de Jiménez Arroyo, las autoridades estatales están a favor de ciertos cárteles según su conveniencia política y económica. Cambian de patrón narco según las posibilidades que les ofrecen; así, el Director de Inteligencia de México comienza una alianza con los hermanos Robles a quienes luego traiciona para unirse a Aurelio, cuando

14 En la telenovela este punto no es tan fuerte como en el libro. Si bien, se mantiene la idea de una ética del narco, Casillas, como villano de melodrama, rompe con ella en reiteradas ocasiones. El momento emblemático de este quiebre es el asesinato de su padrino don Neto. No obstante, se mantiene la recompensa económica y de amparo a sus empleados leales y en la segunda temporada se arrepiente de haber eliminado a su padrino. Así, a pesar de su distanciamiento con esta moral, perpetúa algunos puntos, de la misma forma en que el código sigue vigente y respetado por otros capos.

15 José María Romero Valdivia en la novela y en la vida real Jesús Gutiérrez Rebollo, General de División y Comisionado del Instituto Nacional para el Combate de Drogas (INCD), quien durante varios años mantuvo nexos con Amado Carrillo Fuentes y en el año 1997 fue sentenciado a más de 70 años de prisión bajo los cargos de abuso de autoridad, cohecho, delitos contra la salud, violación a la Ley Federal contra la Delincuencia Organizada y acopio de armas. Actualmente cumple su condena en el penal federal del Altiplano Cf. Hernández, 2014. 
este le ofrece más garantías. Si los mismos representantes del Gobierno se alían con los jefes de la droga, la credibilidad del Estado, así como de sus autoridades, se vuelven nulas. El narcotráfico es tan poderoso que se transforma en una institución paralela y la verdadera soberanía recae en los capos.

Como último bastión de la estructura melodramática, de esta corrupción se mantiene inmune en la telenovela, el Presidente de la República, César Silva, quien se muestra como un hombre íntegro, al contrario de su primo Ramiro, quien también termina negociando con el Señor de los cielos. La telenovela como exponente de valores debe proteger, así, a la máxima autoridad del país, aunque en la vida real es dudoso que Carlos Salinas de Gortari, alter-ego de César Silva, no haya mantenido relaciones con el narcotráfico, puesto que fue acusado de que durante su Gobierno obtuvo beneficios de ciertos jefes de la droga que, incluso, se presume pagaron la propaganda electoral. Ello sumado al hecho de que su hermano Raúl Salinas -Ramiro en la telenovela-- fue detenido en el año 1995 por lavado de dinero ligado al narcotráfico (Cf. Agustín, 1998).

La unión entre autoridades y narcotraficantes deriva en una completa impunidad. El Señor de los cielos es amo y dueño del territorio hasta el punto de hacer y deshacer a su antojo. En la novela, Damián Torres compra a los mandos penitenciarios para poder rescatar a don Benito de la cárcel. Así, aterriza su helicóptero en el patio central de un penal de máxima seguridad, uno de los más impenetrables del mundo, se dice. Posteriormente, cuando es él quien es detenido y es encarcelado, entra como un verdadero héroe. Señala el autor:

El Señor de los Cielos sabía que su casa era el penal completo y podía hacer lo que se le diera la gana. Para comenzar, su celda tenía el tamaño de diez celdas normales, con todas las comodidades: cocina, alfombra, cama enorme, televisión por cable, bar, baño con jacuzzi, teléfono, internet y un catálogo de prepagos nacionales e internacionales en el que figuraban actrices y modelos listas para cualquier perversión que se le ocurriera al gran patrón del narcotráfico mexicano (López, 2013, p. 253).

Al igual que en la novela, Aurelio Casillas ingresa en la cárcel por sugerencia de su amigo el General Jiménez Arroyo quien asume el mérito por la captura del narco y él mismo le ofrece todas las comodidades en la prisión. Poco tiempo después, es el mismo General quien logra su salida sobornando a las autoridades para modificar el expediente, con el fin de que el capo quede libre de toda sospecha como jefe de un cártel de drogas ${ }^{16}$.

A la par de la corrupción e impunidad que se muestran en estas producciones ficcionales, los policías son representados como seres tan brutales y violentos como

16 El General, en la novela y en la telenovela, es un títere del poder del Señor de los cielos. Él le da y le quita a su antojo, lo utiliza para sus propios fines como derrotar a la competencia en el negocio de la droga o poder aterrizar sus helicópteros en pleno Distrito Federal. A cambio, el General queda como el ganador en la lucha antidrogas: "Yo te voy a poner a todos los cartelitos de juguete que me están estorbando y tú con tus pinches soldaditos, tanquecitos y mamadita y media, vas y les pones en su madre. Presentas a los chingones vivos ante las cámaras de televisión y luego los extraditas" (López, 2013, pp. 261-262). 
los mismos narcotraficantes. Al igual que los capos, están dispuestos a utilizar métodos inconstitucionales como la tortura con el fin de incriminar, incluso, a gente inocente y demostrar, así, que están haciendo correctamente su trabajo en la aprensión de los criminales. En la novela, cuando la policía atrapa a los colaboradores de Torres, estos son agredidos y se señala el horror que provoca en los asistentes el ser testigos de las huellas de brutales torturas: "El mismo director de la DEA se sorprendió ante el cinismo del jefe de la PGR a declarar que los delincuentes se habían resistido al arresto y que las fuerzas del Estado, debido a su peligrosidad, solo habían actuado para proteger su integridad (López, 2013, p. 77).

A lo largo de la novela se indica que la tortura es un método tradicional de las fuerzas policiales, cuyo fin es encontrar a quién culpar como supuesto narcotraficante para proteger a los verdaderos responsables ${ }^{17}$. La violencia utilizada es peor que la de los cárteles, puesto que en este caso no se castiga la deslealtad como lo hacen los capos, sino que se practica contra gente inocente y aleatoria:

Camionetas atestadas de personal del Ejército llegan a varios ranchos cercanos al de don Benito. Entran a las casas a culatazos y van requisando lo que encuentran a su paso. A una de las mujeres de Damián, aquella de la que ni el nombre recordaba, la que lo fue a ver al aeropuerto con un niño en brazos, la asustan acusándola de narcotraficante. Pero la mujer no sabe nada de lo que le preguntan, no conoce, ni ha visto al hombre que aparece en la foto que le muestra el del Ejército. Al no lograr su objetivo, le dan un culatazo haciendo que la mujer caiga al piso con el bebé (López, 2013, p.226).

En este pasaje se demuestra la lealtad a toda prueba de la gente a quien el narcotráfico ampara, ya que, a pesar de que Torres no la reconozca como esposa y se indique que ni siquiera recordaba su nombre, ella no cede a la presión policial, no delata al hombre ni a aquellos a quienes les debe la posibilidad de comer. La policía, en cambio, es violenta por opción, agrede a todos los que se encuentran en su camino. No respetan la propiedad privada ni sienten pudor al maltratar a un niño. Al igual que la mujer, los campesinos jamás delatan al patrón, tal como se consigna; aunque ellos no hayan recibido entrenamiento militar para soportar las torturas, recibieron el mejor entrenamiento: el agradecimiento (López, 2013, p. 231).

17 Denuncias de este tipo se han hecho también en la realidad, principalmente, a raíz del Operativo Conjunto Chihuahua, impulsado en el 2008 por el entonces Presidente Felipe Calderón en la guerra contra el narcotráfico. Tal como señala un visitador de la Comisión Estatal de Derechos Humanos, Gustavo de la Rosa: "[Los militares] Obtienen información con las torturas más crueles: de la tanda de golpes pasan a simular ahogamiento; les cubren la cabeza con bolsas llenas de agua para que sientan más rápido el efecto del ahogo y para que se atraganten y el plástico se les pegue. Después, descargas eléctricas con picanas. Más tarde, con un aparato que produce una descarga parecida a la de un rayo; luego a meterlos a los camiones congelados hasta siete horas. A quienes quieren consignan ante un juez, muchas veces con montajes de delitos, redactando un parte falso sobre los hechos, cambiando la fecha y el lugar de detención y sin evidencia, inventando que los detuvieron con armas y drogas" (Páez Varela, 2009, p. 160). 


\section{De narcos y policías}

Se evidencia en los pasajes de la novela y las escenas de la telenovela que policías, autoridades del Gobierno y narcotraficantes no son tan distintos. Todos agreden para conseguir sus fines, todos practican métodos brutales para obtener confesiones. Incluso el mismo héroe de la telenovela, Marco Mejía, cede ante la seducción de la violencia en el momento en que tiene a Aurelio en una camilla, luego de su infructuosa cirugía de cambio de rostro. Amarrado por completo y aún anestesiado Casillas no puede defenderse; es entonces cuando Mejía amenaza con matarlo con un objeto corto-punzante. El capo le indica que eso es un abuso de poder y que por ello podría denunciarlo ante sus superiores; el policía, no obstante, le recuerda que una vez muerto no podría denunciarlo ante nadie. El narcotraficante le recalca que ambos disfrutan la violencia y por esa razón escogieron sus respectivos caminos: él en el negocio de la droga y Marco en la policía.

Narcos y policías parecen ser el reverso de una misma moneda. Ambos son violentos, ambos persiguen el poder y la gloria. Sin embargo, queda claro en estas representaciones ficcionales que mientras los capos tienen una moral, un código, los policías simplemente son títeres que se mueven según sus conveniencias. Incluso el mismo héroe de la telenovela, Marco Mejía, aunque cree en la institución y en el Gobierno, no actúa tanto por salvar al país de la amenaza de la droga, como por sus motivos personales de venganza. De ahí su obsesión por atrapar a Casillas en desmedro de otros cárteles tan poderosos como el de Aurelio.

Esta similitud entre narcotraficantes y autoridades se la hace ver el General Romero Valdivia a Damián Torres en la novela. El capo, no obstante, responde: "no somos iguales. La gente sabe a qué me dedico, mientras que tú, y algunos de tu Gobierno, engañan al mundo entero enriqueciéndose con la farsa de que hacen las cosas en nombre de la patria" (López, 2013, p. 82). La sinceridad, el código moral, una ética es lo que los hace diferentes. Mientras la institución estatal engaña creando una imagen de seguridad, estabilidad y protección, la institución del narcotráfico de verdad protege a su gente y promulga la lealtad y la solidaridad ante todo: "Es mejor ser narco con huevos que un vulgar agente sin palabra, sin decencia, sin códigos de ética" (López, 2013, p. 216), increpa Torres a Juan Marcos. Mientras los narcos y su gente mantienen el silencio a pesar de sufrir golpes y torturas, los policías delatan y las autoridades se cambian de bando constantemente. Mientras Juan Marcos, luego de ser agredido brutalmente cede y da el nombre y la dirección de su jefe, el agente Castillo, don Benito en las mismas circunstancias no declina: "don Benito a esas alturas de la golpiza lo único que buscaba era morir, y la forma más honrosa, segura y certera de hacerlo era insultando al Ejército y a los perros de la policía" (López, 2013, p. 240).

Esta ética de los narcotraficantes también se ve reflejada en la telenovela, a la que se le añade una fuerte consciencia social y empatía con los marginados. Aurelio Casillas, a pesar de ser un hombre despiadado, tal como se representa, es un villano que deja entrever un lado humano, compasivo y reflexivo respecto al rol que cumple en la sociedad. Él no es un narcotraficante por dañar al resto, sino un hombre que fue un niño pobre y que luchó 
contra todos para salir de esa condición, una lucha con el mismo Gobierno que le negó las oportunidades de surgir a él y a su gente. Un hombre comprometido con su familia y su pueblo, solidario y leal. Detrás de tanta violencia hay un discurso social, tal como se refleja en una conversación que sostiene con Marco:

Marco: Siempre me he preguntado si la escoria como tú no siente un poco de remordimiento por todas las cosas malas que ha hecho, por todas las muertes que ha provocado.

Aurelio: Está bien chistoso que digas estas cosas cuando ustedes son parte de todo esto. ¿Qué dignidad tiene un policía si se vende por unos cuantos pesos?

Marco: [...] Da la casualidad de que no todos los policías somos corruptos. ¿̇Tú sabes la cantidad de gente que se muere por las porquerías que venden?

Aurelio: ¿Sabes la cantidad de gente que se muere por las armas que fabrican; por el hambre y por la pobreza?

Marco: Precisamente un hombre tan brillante como tú, ¿por qué dedicarse al mal? pudiste haber sido empresario.

Aurelio: Tú pudiste haber sido cajero de un banco y mírate.

Aurelio, como la mayoría de los personajes de estas narraciones, no cree en las instituciones gubernamentales, no cree en un Estado protector ni en una educación formal. No cree en un trabajo honesto porque sabe que no hay oportunidades reales. No presenta remordimientos por lo que hace porque no se siente diferente a los mismos policías que promulgan una paz que después ellos mismos quiebran con armas y con el uso de la tortura. Cuando su hermano Víctor le pregunta si ha valido la pena tanta sangre él no duda: "¿Qué prefieres, Chacorta, trabajar toda tu vida como bestia para que te paguen dos pesos y que cualquier imbécil te haga sentir menos? ¿Que tus chamacos se estén muriendo de hambre? No Chacorta, ni volviendo a nacer".

\section{Conclusiones. La alternativa a un Estado anómico}

Tal como se indicaba anteriormente, la telenovela busca representar un acontecimiento social, pero también una ideología y una moral que en el caso específico del género policial deriva en la represión de un acto delictual. No obstante, El señor de los cielos pareciera infringir por completo este modelo melodramático de premio y castigo. El villano, Aurelio Casillas, es quien sobrevive y vuelca todo su odio en una expresión de mayor violencia contra todos lo que lo han traicionado, exceptuando, por supuesto, a su mujer Ximena, a quien perdona para salvar a su familia. El héroe, en cambio, quien debiera salir airoso en la captura del criminal, es asesinado a balazos por Heriberto, el hijo del traidor. Marco Mejía, el estandarte de la moralidad, el policía incorruptible, es eliminado.

La muerte del héroe en manos del villano pareciera derribar por completo las convenciones del género melodramático, donde el malvado tiene, por lo general, dos desenlaces posibles: la conversión/ arrepentimiento o la muerte/ castigo. El castigo puede ser el encarcelamiento, la ruina o algún tipo de discapacidad física. La bondad, en 
cambio, debe siempre triunfar sobre lo malo (Monterde, 1994). Este final esperado para toda telenovela tiene su fundamento en que, al estar vinculado a nuestra cotidianidad, ostenta como función el transmitir refuerzos valorativos y aspiracionales, representados por el personaje del héroe que triunfa por sobre la maldad del antagonista. Como señala el académico Roman Gubern:

El espectador vive en realidad un desdoblamiento proyectivo, de modo que se siente solidario y se identifica con el personaje positivo, en quien ve a su semejante, digno de su simpatía, mientras que libera sus frustraciones y sus ansias destructivas a través del personaje malvado, del transgresor moral (Verón y Escudero, 1997, p. 34).

Al contrario, en esta telenovela en particular, como televidentes agradecemos que el transgresor moral se libre, puesto que la verdadera identificación no está con el héroe, que lucha del lado de un Gobierno en decadencia, corrupto y sin valores, que está del lado de un Estado anómico, sino con el villano que, a pesar de toda la violencia con que actúa, es sincero, valiente y es parte de una institución que sí tiene un código, que sí protege, que sí ampara y que sí ofrece oportunidades.

En la novela es Damián Torres el verdadero héroe porque el Estado no ofrece a sus habitantes ninguna posibilidad de surgir, sino, por el contrario, los atormenta, los expone a una violencia sin justificación para salvar a los verdaderos enemigos. Toma chivos expiatorios con el fin de disimular su ineptitud. El narco, en cambio, a través del retrato de sus grandes capos se muestra como institución con ética, con valores y cuyo propósito es salvar al pueblo de la miseria en la que el Gobierno los ha sumido.

En la telenovela, aunque Casillas es el villano y Mejía el héroe, la conclusión es la misma: las instituciones oficiales no funcionan, policías y narcotraficantes no son diferentes, y ello se refleja hasta tal punto que el resultado es que los héroes mueren y los villanos triunfan. La metáfora de una desilusión extrema, el fin de los metarrelatos, entendido según la concepción de Lyotard (1979) como la caída de un discurso legitimador, incredulidad respecto a aquello que debiera protegernos, la destrucción del metarrelato del Estado que termina por destruir los lazos sociales y deja individuos dispersos, que deben valerse por sus propios medios para sobrevivir, puesto que nada ni nadie les asegura ni siquiera los elementos básicos de subsistencia.

La telenovela tradicionalmente ha intentado reflejar valores universales, fecundar, promover y fijar ideas que dan cohesión a la comunidad al aportarnos significados compartidos. Hablarnos de nosotros mismos, ayudar en la construcción de una sedimentación de un determinado pensamiento, entregar una explicación de los que somos y lo que podemos llegar a ser -como individuos y como sociedad-por la vía de la entretención. Tal como descubriera Carlos Monsiváis (2000) en esto radica su alto poder subversivo, como la construcción de un imaginario que recoge las aspiraciones y los intereses de los espectadores. Al ser una "escuela" de sentimientos y valores se nos permitiría educarnos a través de sus referentes. La telenovela, como máxima expresión del melodrama, nos hace imaginar con referentes reales, nos hace aprender de ellos, a la vez que suscita diálogos sobre problemáticas sociales que otros medios no favorecen de 
la misma manera al no contar con un público cautivo tan amplio y heterogéneo. Es por ello que no resulta gratuito que el héroe caiga y el villano triunfe.

La representación de un Estado anómico, en decadencia, el ocaso de una institución de prestigio que ya no protege a sus ciudadanos y que, por el contrario, los intimida y violenta, provoca que como espectadores no sintamos la misma simpatía por el héroe que por el villano y que, más allá de equipararnos con alguno de los personajes, seamos partícipes de la frustración frente a este sistema corrompido. El villano se erige en el verdadero protagonista puesto que es quien lucha por surgir en un medio adverso. En una sociedad corrupta, viciada y sin esperanzas de cambio, Aurelio Casillas es el ideal, quien porta valores trascendentales como la fuerza, valentía, ambición, deseos de superación, amor por sus cercanos, solidaridad y empatía con los excluidos como él.

Así, al referir que el verdadero héroe no es Marcos sino Aurelio no proponemos que la telenovela promueve que el narco y sus capos son hoy por hoy los verdaderos ídolos, sino que revela y denuncia que las instituciones gubernamentales han perdido credibilidad ante la existencia de un Estado anómico. La elección, de esta forma, no está entre identificarse con los buenos o con los malos, porque al fin y al cabo no existe una gran diferencia en métodos e ideales, sino en sentirse representado por un Estado desintegrado que busca sus propios beneficios, frente al espíritu de lucha de Casillas y ese camino que permite morir con orgullo y otorgar mejores condiciones a las nuevas generaciones.

La telenovela, así, como estructura melodramática mantiene la oposición entre buenos y malos, solo que en este caso, trasciende a los héroes y villanos para instalarse también en las instituciones. Un héroe no sirve si lucha solo. Debe existir una colectividad que lo ampare y ayude en su batalla, gente que perpetúe su legado para que este no haya sido en vano. Nada de lo que Marco posee al depositar su confianza en un Estado que lo defrauda una y otra vez. El policía es un héroe cuyo único final posible es la muerte.

Así, la función moralizante de esta telenovela estaría en su denuncia de un Estado anómico, a la vez que plantearía la violencia (tanto de capos como de autoridades gubernamentales) como una consecuencia lógica frente a esta decadencia, una violencia que se daría en dos ámbitos que, a simple vista parecerían opuestos, pero que responden a la misma frustración frente a un Estado que no ampara: la asunción del narcotráfico como institución paralela y la acción agresiva de sujetos particulares que buscan justicia por sus propios medios. De esta forma, no resulta extraño que Leonor, para adquirir el rol de verdadera heroína en esta segunda temporada, primero deba operar al margen de la legalidad, puesto que pesa en su contra una orden de captura y extradición interpuesta por el mismo Gobierno y luego, debe pasar varios años en prisión por un crimen que cometió en defensa propia. Para ser realmente una heroína debe instalarse del lado de lo ilícito batiéndose de igual a igual con Aurelio Casillas. La conclusión de Waldmann (2004) no sería errónea al señalar que "La justicia por mano propia es un fenómeno muy extendido, y un Gobierno que no puede dejar satisfechos a sus ciudadanos tiene que contar con que estos se rebelen de manera más o menos violenta contra los órganos y las instituciones estatales" (111). El señor de los cielos es un ejemplo de ello. 


\section{Referencias bibliográficas}

Agustín, J. (1998). Tragicomedia mexicana 3. La vida en México de 1982 a 1994. México, D.F.: Editorial Planeta Mexicana.

Andrade Bojorges, J. A. (1999). Historia secreta del narco. Desde Navolato vengo. México, D.F.: Editorial Océano.

Carreño, J. (2013). Revelan en EU que CIA grabó tortura a Enrique Camarena. Recuperado el 19 de junio de 2014. Disponible en: http://www.excelsior.com.mx/nacional/2013/10/12/923092

Esquivel, J. (2013). La historia secreta detrás del asesinato de Camarena. Recuperado el 19 de junio de 2014. Disponible en: http://www.proceso.com.mx/?p=355922

Fuenzalida, V.; Corro, P. y Mujica, C. (2009). Melodrama, Subjetividad e Historia: ensayos sobre la ficción cinematográfica y televisiva chilena en la década del 90. Santiago de Chile: Pontificia Universidad Católica de Chile y Consejo Nacional de la Cultura y las Artes-Fondo de Fomento del Audiovisual.

Giavedoni, J. G. (2012, enero-abril) "Del Estado en crisis a la crítica del Estado. Diálogo en torno a la perspectiva del Estado y la gubernamentalidad en el análisis de la nueva cuestión social en América Latina". Revista Mexicana de Ciencias Políticas y Sociales, Universidad Nacional Autónoma de México, Año LVII, N. ${ }^{\circ}$ 214, pp. 89-109.

Gubern, R. (1997). "Fabulación audiovisual y mitogenia". En Verón, E. y Escudero, L. (eds.) Telenovela, ficción popular y mutaciones culturales. Barcelona: Gedisa.

Hall, S. (1997). "El trabajo sobre la representación". Representation: Cultural Representations and Signifying Practices. Londres: Sage publications.

Hernández, A. (2014). Los Señores del Narco. México, D. F.: De Bolsillo.

López, A. (2013). El Señor de los Cielos. México, D. F.: Prisa Ediciones-Aguilar.

Lyotard, F. (1979). La condición postmoderna. Informe sobre el saber. Madrid: Cátedra.

Mauleón, H. (2014). El asesinato de Luis Donaldo Colosio. Recuperado el 19 de junio de 2014. Disponible en: http://www.nexos.com.mx/?p=15685

Monsiváis, C. (2000). Aires de familia. Cultura y sociedad en América Latina. Barcelona: Anagrama.

Monterde, J. E. (1994, abril) "Dossier: El Melodrama". Revista Dirigido. Barcelona: ARCE. N. ${ }^{\circ} 22$.

Munizaga, G. (1975). La teleserie policial: una moral de la violencia. Santiago de Chile: Pontificia Universidad Católica de Chile.

Páez Varela, A. (2009). La guerra por Juárez. México, D. F.: Planeta.

Pimentel, L. R. Tragedia y héroe trágico: la suprema complicación. Recuperado el 5 de junio de 2014. Disponible en: http://www.lpimentel.filos.unam.mx/sites/default/files/textos/tragedia.pdf

Sepúlveda, F. (2003). Análisis y evolución del guion en las teleseries chilenas. Tesis para optar al Título de periodista y al grado de Licenciado en comunicación social. Valdivia: Universidad Austral de Chile. Recuperado el 10 de junio de 2014. Disponible en: http://cybertesis.uach.cl/tesis/uach/2003/ffs479a/ pdf/ffs479a-TH.back.2.pdf 
Trejo Silva, M. (2011). La telenovela mexicana. Orígenes, características, análisis y perspectivas. México, D. F.: Editorial Trillas.

Waldmann, P. (2003). "¿Protección o extorsión? Aproximación al perfil real de la policía en América Latina". En P. Waldmann (ed.). El Estado anómico. Derecho, seguridad pública y vida cotidiana en América Latina. Caracas: Nueva Sociedad.

Waldmann, P. (2004). "Sobre el concepto de Estado Anómico". En W. L. Bernecker (comp.) Transición democrática y anomia social en perspectiva comparada. México, D.F.: El colegio de México, Centro de Estudios Históricos: Servicio alemán de Intercambio Académico: Universidad Nacional Autónoma d México, Facultad de Filosofía y Letras. 